\title{
Fuel cell climatic tests designed for new configured aircraft application
}

\author{
Sylvie Bégot ${ }^{\mathrm{a}, \mathrm{b}}$, Fabien Harel ${ }^{\mathrm{a}, \mathrm{c}}$, Denis Candusso ${ }^{\mathrm{a}, \mathrm{c}, *}$, Xavier François $^{\mathrm{a}, \mathrm{d}}$, Marie-Cécile Péra ${ }^{\mathrm{a}, \mathrm{b}}$, \\ Steen Yde-Andersen ${ }^{\mathrm{e}}$ \\ ${ }^{a}$ FC LAB, Rue Thierry Mieg, F 90010 Belfort Cedex, France \\ ${ }^{\mathrm{b}}$ Franche-Comté Electronique Mécanique Thermique et Optique - Sciences et Technologies (FEMTO-ST), Département énergie et ingénierie des systèmes multiphysiques (ENISYS), \\ Unité Mixte de Recherche (UMR) du Centre National de la Recherche Scientifique (CNRS) 6174, University of Franche-Comté (UFC), France \\ ${ }^{\mathrm{c}}$ The French National Institute for Transport and Safety Research (INRETS), Transports and Environment Laboratory (LTE), Laboratory for New Technologies (LTN), France \\ ${ }^{\mathrm{d}}$ FC LAB, University of Technology Belfort-Montbéliard (UTBM), France \\ ${ }^{\mathrm{e}}$ IRD Fuel Cells A/S, Kullinggade 31, 5700 Svendborg, Denmark
}

The implementation of Fuel Cell (FC) systems in transportation systems, as aircrafts, requires some better understanding and mastering of the new generator behaviours in low temperature environments. To this end, a PEMFC stack is tested and characterised in a climatic chamber. The impacts of the low temperatures over different FC operation and start-up conditions are estimated using a specific test bench developed in-lab.

Some descriptions concerning the test facilities and the experimental set-up are given in the paper, as well as some information about the test procedures applied. Some examples of test results are shown and analysed. The experiments are derived from aircraft requirements and are related with different scenarios of airplane operation. Finally, some assessments concerning the FC system behaviour in low temperature conditions are made, especially with regard to the constraints to be encountered by the next embedded FC generators.

\section{Introduction}

The environmental impacts of the civil air transport are expected to be lowered through the reduction of the airplane fuel consumption, noise and gaseous emissions. In this context, the use of hydrogen as a fuel [1] and the upcoming application of Fuel Cell (FC) systems on board of aircrafts can be considered as a promising option to achieve a step towards a new airplane configuration that will be more environmentally friendly [2]. In that way, FC systems can be proposed as alternatives to the gas turbine based generators, which are currently used. Most likely, the FC technology has also the potential to achieve a real technological breakthrough in the aircraft field. Indeed, FC generators can provide high efficiencies; they can deliver some low nitrogen oxide and carbon monoxide exhausts. Furthermore, the noise reduction in comparison with an Auxiliary Power Unit (APU) based on the current turbine

\footnotetext{
* Corresponding author. Address: The French National Institute for Transport and Safety Research (INRETS), Transports and Environment Laboratory (LTE), Laboratory for New Technologies (LTN), France. Tel.: +33 3845831 36; fax: +33 384583146

E-mail addresses: sylvie.begot@univ-fcomte.fr (S. Bégot), fabien.harel@inrets.fr (F. Harel), denis.candusso@inrets.fr (D. Candusso), xavier.francois@utbm.fr (X. François), marie-cecile.pera@univ-fcomte.fr (M.-C. Péra), sya@ird.dk (S. Yde-Andersen).
}

technology can be significant. However, although these different features make FC systems promising candidates for electrical power supply, the current FC technology cannot meet all the severe requirements of the aircraft applications. For instance, the power weight ratio and the starting time of FC systems have not reached the current APU values yet, in particular if the FC fuel (either hydrogen or hydrogenated mix) has to be supplied from kerosene through a reformer. Beside the necessary cost reduction of the FC generators, another essential task for the future is the improvement of the FC stack and balance-of-plant reliabilities, especially with regard to the possible hard operating constraints encountered in aircrafts. In particular, the flight conditions lead to very low ambient temperature conditions during cruising [3]. Some large temperature variations exerted on the airplane structure can also be encountered during start and landing.

It is obvious that the FC stack operation and start-up from a subzero environment remain challenging tasks for the implementation of FC generators into airplanes. This can briefly be explained by considering some basic physical principles linked with the FC behaviour. During the Proton Exchange Membrane (PEM) FC operation, the reaction of oxygen reduction produces some water, mainly in the cathode compartment of the FC stack. Besides, the reactive gases feeding the PEMFC stack equipped with membrane materials based on perfluorinated ionomers (such as Nafion ${ }^{\mathrm{TM}}$ ) 
have to be humidified prior they enter into the cell assembly [4,5]. In normal (ambient) conditions, the water can normally be removed by the gas flows. But at subzero temperatures, the water can form some ice. This frozen water can partially block the passage of the reactants towards the reaction interfaces, for instance in the channels of the gas distributive plates or through the porous medium of the Gas Diffusion Layers (GDLs) [6,7]. The water turned into ice can coat the catalyst, especially at cathode and may hinder the electrochemical reaction [8]. In worst cases, the frost can even lead to the FC shut-down. It is also reported in the literature that the ice can damage the materials of the Membrane Electrode Assemblies (MEAs) and that some ice particles may lead to the formation of cracks in the membranes [9]. The frost can change the contact properties at the interfaces between the MEA various layers: GDLs, electrodes and membranes due to delamination effects. Moreover, before that a nonoperated FC stack is stored inside a cold surround, some specific drying or purging methods have to be usually adopted in order to drive out the residual water contained in the flow fields and in the porous components of the FC [10].

A growing number of research teams is involved in works, which aims generally consist in getting some deeper and more fundamental understanding of the frost formation mechanisms within the FC assembly operated or started-up in subzero temperature environment. FC modelling and theoretical analysis are needed to elucidate the electrochemical and transport mechanisms during cold start below the freezing temperature. In [11], Wang investigates the heat/mass transfer and electrochemical kinetics in the cathode catalyst layer of PEMFCs during cold start. A number of key parameters that govern the cold-start operations, such as time constants, are defined and their impacts are explored through modelling. In this work, the reduction in the electrochemical active surface of the electrode catalyst layer due to the ice coverage is found to be a major mechanism leading to cell voltage loss during cold start. Obviously, FC testing is also highly needed to elucidate the electrochemical and transport mechanisms occurring below the freezing temperature. Especially the works focusing on material aspects are crucial for the development of FC stacks that enable proper operations and start-up phases in the cold surrounds. Most of the related experimental investigations are done ex-situ (i.e. on FC materials and components [12]), sometimes with nonoperating FCs $[13,14])$ or in situ but on single PEMFCs with limited electrode active area (area of a few $\mathrm{cm}^{2}$ only) [15-17]. Some works are also conducted on FCs with different electrode dimensions. In [18], two single cells ( 4 and $128 \mathrm{~cm}^{2}$ electrode active area) were started by Wang et al. from a subzero temperature. By applying reverse voltages, the effects on the MEA of reverse voltage and frozen FC startup were investigated. If a consequent number of studies is now carried out on small single cells, experiments done on larger FC assemblies are still infrequent (for cost reasons and due to the complexity of the testing). However, FC stacks lead to power levels which are more compatible with transport applications and when operated under transportation constraints, they bring to the fore some points that cannot be seen on single cells. For example, in cold surrounds, nonhomogeneous temperature distributions can appear in the cell assembly: the temperature in the centre of the stack can be higher than in the end cells [19]. Actually, only a few research groups work with FC stacks $[19,20]$. In [21-23], Oszcipok et al. studied the cold start of a six cell stack for portable applications. In [20], some significant influencing parameters were defined and investigated by Eva Schießwohl et al. in order to improve the freeze start ability of a FC system. Experiments with a FC test system were carried out in a climate chamber in various conditions. The integrated stack consisted of 60 individual cells with graphite bipolar plates and had a maximum electrical power of $2.6 \mathrm{~kW}$. Datta et al. [24] have also reported on a successful cold start-up and operation of a $500 \mathrm{~W}$ PEMFC generator during 10 days at $-35^{\circ} \mathrm{C}$, but only little detailed information have been provided on the system control.

Besides, beyond the power levels of the investigated FCs, it is also important to note that many freeze start-up experiments are performed in isothermal conditions [21-23,25-27] which are certainly helpful to obtain a better knowledge of the physical mechanisms involved but not necessary representative of the true conditions linked with vehicle applications and FC start-up strategies. The impacts of the various ancillaries dedicated to the fluid and energy conditioning over the FC stack operation must also be evaluated at the FC system level, by considering not only the stack itself but also its peripheral equipments, some different electrical control laws and gas/water management strategies related with the complete system [19]. The system design, the control of the ancillaries (e.g. the design of the FC temperature circuit and the control of the pump on the temperature loop) are of main importance to achieve successful start-up and shut-down phases of FC generators in cold surrounds. In [20], the shut-down strategy of the FC system is identified to be one of the main parameters influencing the freeze start.

In the framework of the European Strep project CELINA (fuel cell application in a new configured aircraft $[28,29])$, some experimental investigations have been conducted with a PEMFC stack placed in low temperature environments. The climatic tests were designed according to different scenarios of aircraft operation and the effects of the cold surrounds were estimated to better define the suitability of a today's PEMFC assembly.

The article is organised as follows: the paper starts with the descriptions of the studied FC stack and experimental set-up. Then, some examples of climatic test results are presented and discussed. Some assessments concerning the stack behaviour in low temperature conditions are made, and some outlooks are proposed for future experimental studies.

One of the main objectives of the article is to show that experimental works conducted at the system level of a FC generator (with a significant level of electrical power for vehicle applications) are of major concern, first to better identify the real operation constraints applied on the FC system and then to propose some technological solutions that will enable the future PEMFC implementations into aircrafts and terrestrial vehicles as well.

\section{Experimental}

\subsection{The fuel cell}

The investigations were led with a PEMFC stack delivered by IRD [30] and not built up especially for freeze start experiments. It is composed of 52 cells assembled with commercially membranes (active cell area of $156 \mathrm{~cm}^{2}$ ), Gas Diffusion Layers (GDLs) and machined flow field plates made of graphite compound. The stack is placed in a plastic housing to prevent convective heat exchange with the ambience. In nominal conditions, the FC shall be operated at temperature levels close to $60^{\circ} \mathrm{C}$ and fed by humidified hydrogen and air, with relative Humidity Rates (HR) of $90 \%$ at the stack temperature. Anode/cathode stoichiometry rates (FSA/FSC) shall be near $1.5 / 2.5$. The FC can operate either at atmospheric pressure or at higher pressure (up to 3 bar abs.). At these pressures and around nominal conditions, the stack can deliver some electrical power levels of about $2.5 \mathrm{~kW}$ and $3.5 \mathrm{~kW}$ respectively.

\subsection{The test bench}

The test bench is made of two different parts. The first, and main one in terms of volume or place occupancy, is made of the 
complete gas conditioning systems (i.e. gas flow and pressure controls, gas humidification systems, etc.), the electronic load, and the electric/electronic management system. The second and smaller part is a specific module, which is equipped with the FC stack to be investigated and that can be placed inside the climatic chamber. This specific unit includes notably the FC primary water circuit dedicated to the control of the temperature inside the stack assembly. Following the requested stack temperature, this water circuit can ensure either the heating or the cooling of the FC. The loop is made of an electrical heater, a heat exchanger (coupled with a secondary cold water circuit, which fluidic temperature equals about $10^{\circ} \mathrm{C}$ ), actuators (a pump to move the fluid inside the loop, a three-way valve to mix the hot and cold fluids together), temperature and pressure sensors at stack inlets and outlets. The separated module includes also some temperature and pressure sensors on the gas lines (located at stack inlets and outlets) as well as some relative humidity sensors (both at stack inlet and outlet for the air side; only at stack inlet for the hydrogen side). A simplified flow-chart of the test bench is depicted in Fig. 1. The equipment and in particular the small module inside the climatic chamber can be observed in Fig. 2. The IRD stack can be perceived on the right of the picture. It is supported vertically on the module. The main piece of the test bench can partly be seen on the left of the photography. Some gas pipes, the cold water circuit, as well as various electric cables are connected between the two parts of the set-up.

The test bench allows testing the FC in different operating modes (flow-through or open mode, dead-end mode) and for different operating parameters (gas pressure, stack temperature, anode/cathode stoichiometry rates, humidification rates for the reactive gases, electronic load level). Some additional information about the bench, with more details about the fuel, the oxidant and the control temperature loops, is given hereafter. Further explanations are also given concerning the electronic load and regarding the safety aspects as well.

\subsubsection{Hydrogen line}

Hydrogen is stored in high pressure tanks (at 200 bar) located outside of the FC test platform. The fuel line of the test bench is fed by the room facilities, which deliver a pressure of 8 bar. An expander decreases the pressure between 1 and 2 bar (relative pressure). A flow rate controller enables the control of the hydrogen flow. A second flow controller can also be used in order to inject another gas, nitrogen for instance, into the hydrogen stream so that a reformat mix or a diluted fuel can also be simulated. The two flow controller devices allow setting the right amount of dry gases. Note that a purge gas system fed by nitrogen is also used for the inerting of the fuel line. Downstream the flow controllers, the gases can either be humidified or kept dry. In the second case, the gas hydration system is bypassed.

The adopted humidification system is based on injection of deionised water into the gas. This system was initially a part of a $10 \mathrm{~kW}$ test bench available on the FC test platform of Belfort [31]. It has been modified and adapted to the test bench used in the framework of the CELINA project. The operation principle is the following one. Some deionised water (up to $1 \mathrm{~kg} \mathrm{~h}^{-1}$ ) is injected into an evaporator and then enters into a heated column where the reactive gas circulates (Fig. 1). The controlled fuel flow enters at the bottom of the column while a controlled (vapour) water stream is injected at the top. As the gas rises, it gets humid. Vapour exchange between the fuel flow and the water flow is favoured by metallic rolls inside the column. The water quantity to be injected can theoretically be computed versus the fuel temperature in the column, the gas pressure and flow as well as the required humidity rate. As a dynamical humidity transmitter (supplier: JUMO, reference: Vaisala HMT337) is placed at anode stack inlet, the water quantity to be injected can also be adapted by the test bench user in order to get the right gas humidity level. (Note that the humidity sensor is not yet involved in the process regulation.) A bleeder, which is located at the column bottom, collects the part of the water, which could not been transferred to the fuel.

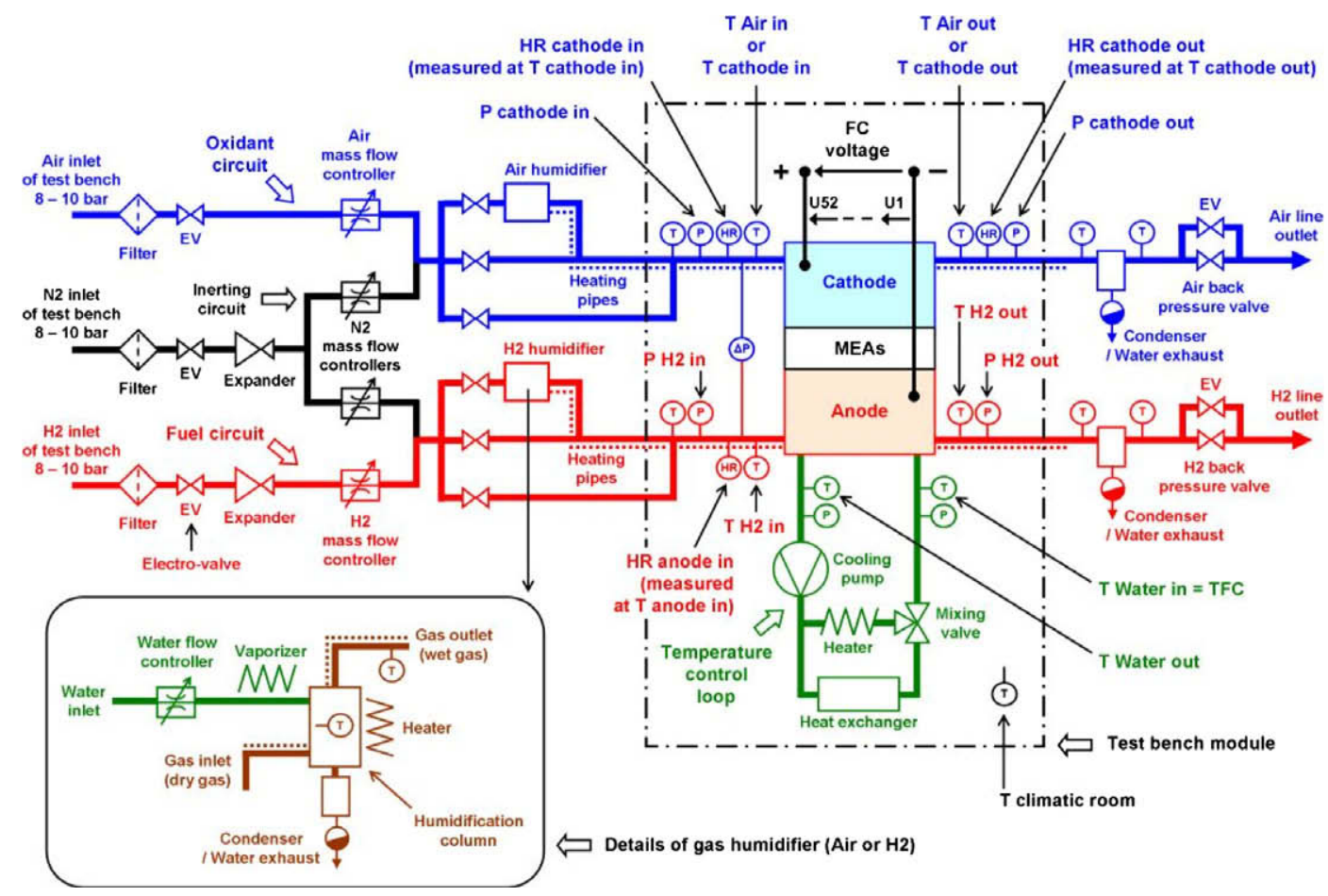

Fig. 1. Simplified scheme of the FC test bench. 


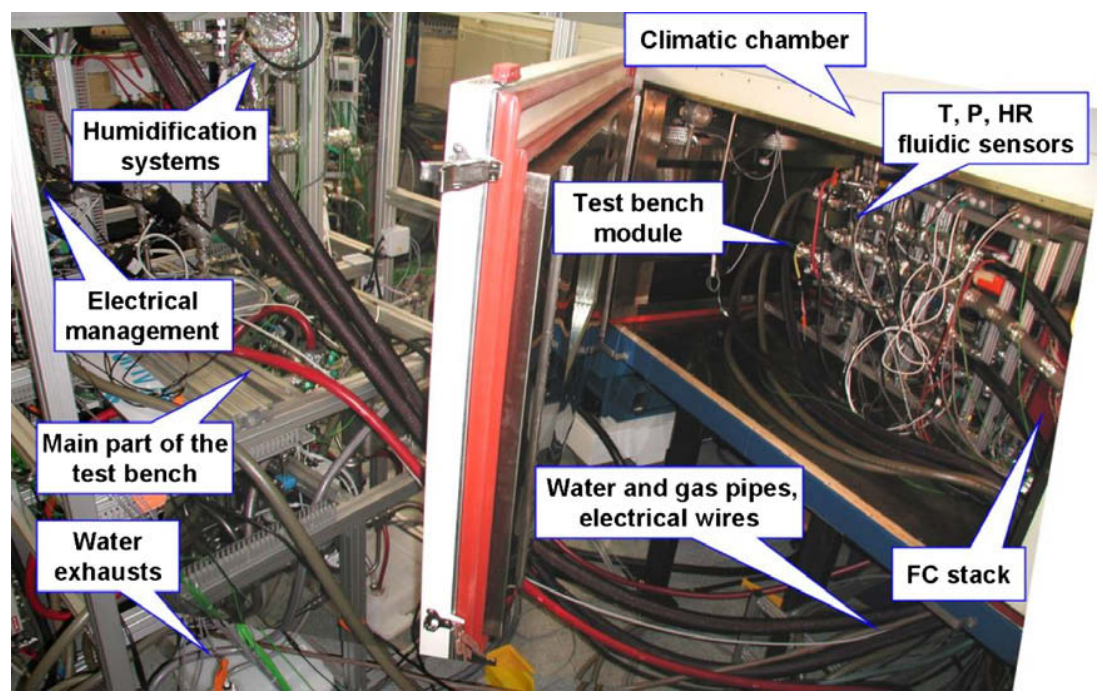

Fig. 2. Picture of the FC test bench.

Upstream of the stack, the hydrogen temperature is kept constant, first by a heater cable placed along the stainless steel pipes coming out of the humidification system and then, using a flexible heated line that ensures the connection between the main part of the bench and the small test module (Fig. 2). The fuel pressure, temperature and relative humidity are measured on the small module equipped with the FC at the stack inlet. Note that the relative humidity $H R$ anode in is measured at the fuel inlet temperature. This relative humidity can be transposed/computed for the temperature value $T$ water in $=T F C$ measured for instance at the stack inlet of the temperature control loop. In this case it is noted HR anode in TFC and estimated by (1) and one possible expression of the saturation pressure (2) (Antoine's Law formula with temperature $T$ expressed in $\mathrm{K}[32])$

$H R$ anode in $T F C=H R$ anode in $\times$ Psat $(T$ anode in $) / P s a t(T F C)$

With: $\quad \operatorname{Psat}(T)=\exp (23.1961-3816.44 /(T-46.13))$

At the stack outlet, the gas pressure and temperature are measured again. Then, the back-pressure valve allows selecting one of the three operating modes. In the first mode, the valve is completely opened (open mode). Thus, the stack outlet is nearly at the atmospheric pressure and the stack exhaust is thrown up outside. The reactive gas flow is controlled by the flow controllers placed upstream of the stack and already mentioned above. In that way, the anode stoichiometry rate can be set. This flow-through mode allows measuring the impact of the fuel utilisation on the stack performance. In the second mode (dead-end mode), the valve is completely closed during normal operation and is only opened to flush the stack anode compartment. The flow rate is either set to control the stack pressure (estimated at stack inlet in the CELINA project) or the pressure is just limited by the expander in open loop. In the third mode (pressure mode), the valve is controlled to apply a back pressure on the fuel line. Coupled with the flow rate controller, it allows controlling both the inlet fuel flow and its pressure. Water vapour is finally condensed by a heat exchanger supplied with cold water which lowers the gas dew point to about $12^{\circ} \mathrm{C}$. The water is collected in a tank and the gas flow is evacuated outside.

\subsubsection{Oxidant line}

The air supply is handled by a compressor system located in a technical room of the facilities. The oxidant circuit has the same fluidic topology as the fuel circuit. Air pressures, temperatures and flows are measured at stack inlet and outlet. The oxidant line can be operated either with air or with a mix. In both cases, the oxidant is provided by the test room facilities. A flow rate controller allows setting the dry air flow rate. A back-pressure valve ends the line: it can be either completely opened, the outlet is at atmospheric pressure, or the opening of the valve can be reduced to apply a back pressure and master the pressure level at stack inlet. The valve is never completely closed to blow out the gas and the water coming out of the FC as the oxidant (oxygen) is always diluted with inert nitrogen). The humidification system is also based on the principle of the water vapour injection (up to $3 \mathrm{~kg} \mathrm{~h}^{-1}$ ) into the reactive gas and it is located upstream of the stack. Some relative humidity transmitters are located at stack inlet and outlet on the oxidant pipe. The relative humidity rates $H R$ cathode in and $H R$ cathode out are measured respectively at the air inlet and outlet temperatures. Similarly to what is done for the case of the fuel line, the $H R$ cathode in value can be adapted to the temperature level $T$ water in $=$ TFC measured at the stack inlet of the control loop temperature. In this case it is noted: HR cathode in TFC.

\subsubsection{Temperature control circuit}

A cooling medium that can operate at the subzero temperatures (a nonconductive mix of water with ethylene glycol) is used for the climatic tests. The temperature control circuit of the test bench has been designed for stacks that are cooled by an internal water-glycol mix circuit. City water is demineralised to feed this primary loop. The mix is circulated by a pump, which flow is controlled using variable speed. The temperature considered as representative of the stack temperature is the water temperature measured at the stack inlet. A proportional three-way valve is used to master this temperature with as high accuracy as possible. The technology of the valve was initially selected with regards of its ability to be operated at low temperature levels (about $-20^{\circ} \mathrm{C}$ ). Through this valve, the fluid of the cooling circuit is the result of a mix made with the water-glycol medium coming on the one hand from a water/cold water exchanger and on the other hand from a heater.

\subsubsection{Electronic load}

The stack supplies a TDI programmable electronic load.

\subsubsection{Climate chamber}

The climatic room has the following characteristics. The size of the volume useful to place a system is $1.5 \mathrm{~m} \times 1.5 \mathrm{~m} \times 0.8 \mathrm{~m}$. The 
temperatures that can be reached range from $-45^{\circ} \mathrm{C}$ (or $-30^{\circ} \mathrm{C}$ with a $10 \mathrm{~kW}$ thermal dissipation) to $+130^{\circ} \mathrm{C}$. One temperature level can be reached with a ramp rate of about $1{ }^{\circ} \mathrm{C} \mathrm{min}^{-1}$ (without any thermal dissipation of the investigated system). The temperature constancy and the temperature uniformity are equal to $\pm 2{ }^{\circ} \mathrm{C}$. A relative humidity level ranging from $10 \%$ to $97 \%$ can be obtained between $+10^{\circ} \mathrm{C}$ and $+90{ }^{\circ} \mathrm{C}$.

\subsubsection{Life and property safety}

Life and property safety are taken into account by the facilities. The main risk that is considered is linked with the use of hydrogen. The general safety policy is to keep the hydrogen concentration under the explosive limit (4\% in volume). Two hydrogen sensors and two flame sensors are located at the test room roof, for redundancy. The ceiling has been designed with a sharp slope to avoid local hydrogen accumulation. Fresh air is blown at the bottom of the room and is evacuated by natural convection through a chimney. In normal operation, the room is ventilated at 20 volumes per hour. If the hydrogen concentration is measured above $1 \%$, the room hydrogen feeding is automatically shut-down. The fresh air blow is also increased to 40 volumes per hour to evacuate hydrogen. If the facilities cannot be fed by the grid for any reason, vents are opened automatically to have a natural convection anyway. The climate chamber has been specially designed to apply analogous principles. In that way, this equipment has its own hydrogen and heat sensors, as well as an internal ventilation of the volume dedicated to the tests.

\subsubsection{Stack safety}

The stack safety is also taken into account. First, a too high pressure drop between the fuel circuit and the oxidant gas can damage one or several MEAs irreversibly. So, the pressure gap at the stack inlets between anode and cathode is always measured. If this pressure drop reaches the threshold of $500 \mathrm{mbar}$, the fuel and oxidant gas feeding is shut-down. This soft solution is redundant with a hard alternative (differential pressure sensor). The pressure drop information is sent to an electronic card, which shuts down also the reactant circuit electro-valves. In the same way, the maximal pressures at stack inlets cannot exceed 3 bar abs. (according to the specification of the stack manufacturer). The decrease of the voltage across a cell is a sign that the cell operates in wrong conditions. Each cell voltage is thus monitored and surveyed. Two thresholds are applied: an alarm one at $400 \mathrm{mV}$ and an emergency one at $200 \mathrm{mV}$. When either the second one is reached or the stack voltage is below $15 \mathrm{~V}$, the electrical load is shut-down and the gas feeding as well. An emergency stop occurs also in the following cases: if the gas pressures reach the maximal value, if the water pressure reaches the maximal value, - if the stack temperature reaches the maximal value of $80^{\circ} \mathrm{C}$, if the flow of the primary cooling circuit stops, if any sensor data is out of range.

Table 1

Technical specifications of the main actuators and sensors used in the study.

\begin{tabular}{|c|c|c|c|}
\hline Actuators and sensors & Range & Accuracy & Additional information \\
\hline \multicolumn{4}{|l|}{ Electric } \\
\hline Electronic load & $0-100 \mathrm{~A}$ & $\pm 0.5 \%$ of full scale & $\begin{array}{l}\text { TDI WCL } 488-400-1000-12,000 \\
\text { Time response }<25 \mu \mathrm{s}\end{array}$ \\
\hline Cell voltage measurements & Voltage input: $0-2 \mathrm{~V}$ & $\pm 0.3 \mathrm{mV}$ & $\begin{array}{l}\text { Acquisition modules of National Instruments } \\
\text { (SCXI-1125) }\end{array}$ \\
\hline FC current sensor & $\begin{array}{l}0-200 \mathrm{~A} \\
\text { Nominal: } \mathrm{In}=200 \mathrm{~A}\end{array}$ & $1 \%$ accuracy of reading & LEM current transducer type DK200 B420 \\
\hline FC stack voltage sensor & $0-60 \mathrm{~V}$ & $8 \mathrm{mV}$ (maximal) & $\begin{array}{l}\text { Acquisition modules of National Instruments } \\
\text { (SCXI-1125) }\end{array}$ \\
\hline \multicolumn{4}{|l|}{ Fluidic } \\
\hline Fuel mass flow controller & Flow: $0-500 \mathrm{~N} 1 \mathrm{~min}^{-1}$ & $\begin{array}{l} \pm 0.7 \% \text { of the flow value and } \\
\pm 0.2 \% \text { of full scale }\end{array}$ & $\begin{array}{l}\text { Brooks type } 5853 \mathrm{~S} \\
\text { Time response }<1 \mathrm{~s}\end{array}$ \\
\hline Air mass flow controller & Flow: $0-2000 \mathrm{~N} 1 \mathrm{~min}^{-1}$ & $\begin{array}{l} \pm 0.7 \% \text { of the flow value and } \\
\pm 1 \% \text { of full scale }\end{array}$ & $\begin{array}{l}\text { Brooks type } 5853 \mathrm{~S} \text { HD } \\
\text { Time response }<1 \mathrm{~s}\end{array}$ \\
\hline Anode back-pressure valve & $\begin{array}{l}\text { Flow: } 0-250 \mathrm{~N} 1 \mathrm{~min}^{-1} \\
\text { Pressure: } 0-3 \text { bar rel. }\end{array}$ & \pm 30 mbar & Tescom. Reference: 26-2561 \\
\hline Cathode back-pressure valve & $\begin{array}{l}\text { Flow: } 0-1400 \mathrm{~N} 1 \mathrm{~min}^{-1} \\
\text { Pressure: } 0-3 \text { bar rel. }\end{array}$ & \pm 30 mbar & Tescom. Reference: 26-2561 \\
\hline Fuel and air pressure transducers & $0-2$ bar rel. & $\pm 0.5 \%$ of full scale & Keller piezoresistive transmitters PR23S \\
\hline $\begin{array}{l}\text { Anode-cathode differential pressure } \\
\text { transducer }\end{array}$ & 0-200 mbar & $\pm 0.5 \%$ of full scale & Keller transmitter PD23 \\
\hline Water flow controller for air humidification & $\begin{array}{l}0-3 \mathrm{~kg} \mathrm{~h}^{-1} \\
\text { Operating pressure: } 5 \text { bar }\end{array}$ & $\pm 0.5 \%$ of full scale & $\begin{array}{l}\text { Brooks type } 5882 \mathrm{FL} \Omega \text { MEGA } \\
\text { Response time } \approx 7 \mathrm{~s}\end{array}$ \\
\hline $\begin{array}{l}\text { Water flow controller for hydrogen } \\
\text { humidification }\end{array}$ & $0-1 \mathrm{~kg} \mathrm{~h}^{-1}$ & $1 \%$ of reading & $\begin{array}{l}\text { Brooks Quantim QMBC } \\
\text { Response time }<2 \mathrm{~s}\end{array}$ \\
\hline $\begin{array}{l}\text { Thermal } \\
\text { Cooling pump on the temperature control loop }\end{array}$ & $\begin{array}{l}0-7 \mathrm{~m}^{3} \mathrm{~h}^{-1} \\
\text { Nominal: } 4 \mathrm{~m}^{3} \mathrm{~h}^{-1} \\
\text { Pressure: } 3 \mathrm{bar}\end{array}$ & $\pm 31 \mathrm{~min}^{-1}$ & Leroy Somer MIH 4-5 T \\
\hline $\begin{array}{l}\text { Mixing valve on the FC temperature control } \\
\text { loop }\end{array}$ & $\mathrm{kV}=10$ & - & $\begin{array}{l}\text { Samson Type } 3244 \\
\text { DN } 25 \text { PN } 40\end{array}$ \\
\hline $\begin{array}{l}\text { Heat exchanger on the FC temperature control } \\
\text { loop }\end{array}$ & FC maximal temperature: $70^{\circ} \mathrm{C}$ & - & $\begin{array}{l}\text { SWEP B8H } \times 30 \\
\text { Power: } 26 \mathrm{~kW} \text { (for a FC temperature of } 70{ }^{\circ} \mathrm{C} \text { ) }\end{array}$ \\
\hline Temperature sensor & From $-200{ }^{\circ} \mathrm{C}$ to $1250^{\circ} \mathrm{C}$ & $0.2^{\circ} \mathrm{C}$ & $\begin{array}{l}\text { Thermocouple Type } \mathrm{K} \\
\text { Stack temperature control made at stack inlet, } \\
\text { on the water cooling loop }\left( \pm 1^{\circ} \mathrm{C}\right) \text {. } \\
\text { Note that type } T \text { should be preferred for } \\
\text { temperatures lower than }-20^{\circ} \mathrm{C}\end{array}$ \\
\hline Humidity sensor & $40-97 \% \mathrm{HR}$ & Humidity: $\pm 1 \%$ HR & Vaisala HMT337 \\
\hline $\begin{array}{l}\text { Equipped with heated temperature probes } \\
\text { and piezoresistive pressure sensors }\end{array}$ & $0-1$ bar & $\begin{array}{l}\text { Temperature: } \pm 0.1{ }^{\circ} \mathrm{C} \\
\text { Pressure: } \pm 0.05 \% \text { of full } \\
\text { scale }\end{array}$ & $\begin{array}{l}\text { With PT100s } \\
\text { Response time: } 10 \mathrm{~ms} \text { for the pressure sensors }\end{array}$ \\
\hline
\end{tabular}




\subsubsection{Control process and interface}

The control and the data acquisition process are based on $\mathrm{Na}-$ tional Instruments systems (PXI-SCXI set) [33]. The PXI 6070E includes a 12-bit analog digital converter. Each channel is sampled at $1 \mathrm{kHz}$. The complete test bench is operated using a Labview ${ }^{\mathrm{TM}}$ dedicated software, also developed in-lab and which allows setting the operating conditions: open or dead-end mode, control of the flows and/or the pressures, gas hydration levels, stack and gas temperatures, load profile, normal start and normal or emergency shutdown. The operator can set manually all the parameters or can start some automatic procedures. Only the humidification system works in manual mode. The measured information is stored in data files, which can be worked out for instance with MATLAB ${ }^{\mathrm{TM}}$ [34].

Table 1 summarises the technical specifications of the main electric, fluidic and thermal devices/sensors used during the FC tests.

To conclude this subsection, it has to be mentioned that the development of the test bench was a real challenge for the lab, especially because some difficult technological trade-offs had to be defined in order to be able to perform climatic tests. On the one hand, the test data and results had to be sufficiently accurate to enable their exploitations in future modelling phases. Thus, high control performances of the physical variables had to be achieved. On the other hand, the available technologies did not allow getting such accurate controls as there were not necessary for just running stacks. So, specific control strategies had to be designed and implemented to reach this aim and other component choices as well. This problem was emphasised as very particular test conditions (for instance linked with the operation at temperatures lower than $-20^{\circ} \mathrm{C}$ ) were concerned.

\subsection{Fuel cell test scheduling}

Prior to describe the climatic test results in Section 3, a brief sketch of the protocol allowing the FC installation on the test bench and the start-up in usual operating conditions is provided. The main steps of the overall adopted procedure are the following ones.

- The stack has to be installed on the test bench module. The FC fluidic inlets and outlets as well as the various electrical wires (e.g. cables of the external load circuit, for the cell voltage monitoring) have to be connected to the bench. The electrical supply of the test bench can be turn on and the human-machine control interface can then be used.

- The FC temperature circuit has to be filled up with an appropriate cooling medium. The presence of air bubbles remaining in the circuit has to be avoided. They have to be flushed out to ensure the setting of stable cooling flows.

- Some gas leak tests have to be performed, especially to check that no reactive gas can pass from anode to cathode and to detect any possible broken membrane or defective sealing [35,36]. These tests are generally performed by pressurising either the anode or the cathode with nitrogen and by sealing off the two compartments. The pressures at both sides are monitored. If no equilibrium of pressures is detected in the following few minutes, the test can be considered as successful. Conversely, if a major internal leakage is observed, the FC shall be removed from the test bench and the stack assembly has to be verified.

- The availability of the various fluidic media has to be verified (compressed air, hydrogen, nitrogen for inerting phases, demineralised water flows for the humidification systems).

- Then, the various reference values of the physical parameters can be set using the software interface: i.e. stack temperature, FSA/FSC set. .

- Finally, some load currents can be applied to the FC. The current level can be increased gradually and adapted according to the behaviours and performances of the cell voltages. This can be done "manually" by the operator or even automatically using a dedicated start-up procedure that allows intelligent current controls (by avoiding any excursions in the low cell voltage values ranging here from $200 \mathrm{mV}$ to $0 \mathrm{~V}$, according to the stack manufacturer specifications).

- Some additional experiment details as well as the course of the test procedures more specifically related with the climatic tests are given in the following section.

\section{Test results}

Different categories of temperature tests exist for aircraft applications. The selection of a temperature category depends notably on the system location in the airplane, the maximum operating altitude and whether the equipment is located within a temperature and/or pressure controlled area. For FC installation in the tail cone, the category D2 is used in the framework of CELINA according to DO-160D equipment intended for installation in nonpressurised and noncontrolled temperature locations on aircraft [3]. Four kinds of climatic tests have been performed, namely: short reference tests, low temperature tests, ground survival temperature tests and operating low temperature tests. As already mentioned in the introduction, the climatic experiments correspond to different possible FC operations linked with various scenarios of aircraft application.

- The investigated FC stack was also initially operated in reference conditions (e.g. at ambient surrounding temperature close to $+15^{\circ} \mathrm{C}$ ) in order to collect some valid data that can allow comparisons with the test results obtained in different conditions related to specific aircraft conditions, and in particular with the climatic test results.

- The main aim of the low temperature tests is to evaluate the FC stack behaviour in operation at low surrounding temperatures, with a start-up made at ambient temperature (around $+20^{\circ} \mathrm{C}$ ). Besides, it is important to note that the response of the FC at the system level is also evaluated, at least partly, since various components of the test bench and ancillaries (water pump, sensors, valves... of the bench module) located in the climatic chamber are solicited by the test. Even if the test bench module is dedicated to FC characterisation purposes and thus cannot be considered as an actual autonomous, integrated FC generator, some parts of its architecture (e.g. temperature control loop) and some technological components can be drawn nearer of those related with a real embedded system.

- The ground survival temperature test is mainly dedicated to the study of the negative surround temperature impact on the FC stack (and system) when this one is not operated (test bench switched off) during a few hours. In this test, the start-up phase is made from a positive stack temperature $\left(+15^{\circ} \mathrm{C}\right)$, which is obtained without any FC power delivery but with an active heating through the temperature control loop (assisted FC start-up).

- The operating low temperature tests are performed to investigate the start-up of the FC at subzero temperatures. In this case, a passive method [19] is used to heat the stack. This means that ideally only the irreversible heat losses of the FC in operation shall contribute to the heating. This test can also be qualified as self-start [8]. In one alternative way, the stack could also be preheated via its feeding with warm reactants.

Some examples of test results are given hereafter for the four sorts of climatic tests performed. From the results obtained, a discussion is also made about the future FC generators to be embedded in the next generations of aircrafts and possibly subjected to low temperature constraints. In the first subsection, some 
explanations are given concerning the experimental procedure applied to record a short reference test.

\subsection{Short reference test}

The short reference test may be divided into two successive phases: firstly, the increase of the power delivered by the FC and then the operation in steady-state conditions and secondly, some characterisation measurements performed through two polarisation curves by increasing and decreasing the load. Actually, the first phase corresponds to a membrane "resetting" or conditioning procedure. Indeed, before any polarisation test is done, it is generally recommended to operate the FC at steady-state conditions, in order to avoid as far as possible any impact of the recent chronological account on the characterisation measurement. So, during the test, the FC current is increased and then the stack is operated with a load current of $90 \mathrm{~A}$ (so, at roughly nominal electrical power: $2.5 \mathrm{~kW}$ ), at ambient pressure during 15-20 min. The level of the FC temperature is fixed at $60^{\circ} \mathrm{C}$, with the aim of getting the best performances from the investigated stack. The references for the gas inlet temperatures are fixed at $65{ }^{\circ} \mathrm{C}$ and the references for the relative humidity rates of the reactive gases are set to $90 \%$ (for the stack temperature of $60^{\circ} \mathrm{C}$ ). After the conditioning procedure, two polarisation curve records of the reference test are then performed in the following conditions: nearly ambient pressures at anode and cathode outlets, stack temperature reference of $+60^{\circ} \mathrm{C}$, reference for the reactive gas humidity equal to $90 \%$ at $+60{ }^{\circ} \mathrm{C}$, anode/cathode stoichiometry rates respectively equal to $1.5 / 2.5$.

The detailed methodology used for the polarisation curve measurements is the following one. The polarisation record is performed by incrementing and decreasing the FC current by steps of $10 \mathrm{~A}$ in the load current range: $0 \mathrm{~A}$ to the maximal current value (specification: $100 \mathrm{~A}$ ). Before each current step, the gas flows, calculated from the stoichiometry rates corresponding to the new current value, are first prepared in order to prevent any stack starvation. They supply the stack during a period of $5 \mathrm{~s}$. Then, the FC has to supply the new current during the next 150 s. Five seconds after the end of this last stage, the new gas flows are prepared again for the next current step. Some minimum flows are set to an equivalent stack current of $20 \mathrm{~A}$ to ensure a better draining of the water out of the stack and thus a constant operation (without fluctuation) at low power output. All these duration parameters related to the polarisation curve procedure can be specified via the human-machine interface software developed in-lab. The choice of the duration parameters is made in order to get stationary conditions. When either any one of the cell voltages reaches the minimal threshold cell voltage $(200 \mathrm{mV})$ or the stack voltage is lower than $15 \mathrm{~V}$, the polarisation test is stopped.

An example of results obtained during the record of a short reference test is given in Fig. 3. An electrical power of about $2840 \mathrm{~W}$ was reached for the load current of $90 \mathrm{~A}$ at the end of the steadystate phase. A power of $3065 \mathrm{~W}$ was obtained at $100 \mathrm{~A}$ during the record of the polarisation curves.

\subsection{Low temperature tests}

Three low temperature tests have been conducted. The global procedure of the low temperature tests applied is the following one. At the beginning of the experiment, the surrounding temperature (i.e. in the climate chamber, $T$ climatic room) is close to $+15^{\circ} \mathrm{C}$. The stack and gas inlet temperatures equal $60^{\circ} \mathrm{C}$. The reactive gases are humidified (with $\mathrm{HR}=90 \%$ at the stack temperature). The stack is operated in steady-state at a specified load current value ( $25 \mathrm{~A}, 50 \mathrm{~A}$ or $75 \mathrm{~A}$ depending on the test considered). Then, the surrounding temperature is decreased stepwise (with steps of about $-5^{\circ} \mathrm{C}$ ). When the lowest surrounding temperature level is

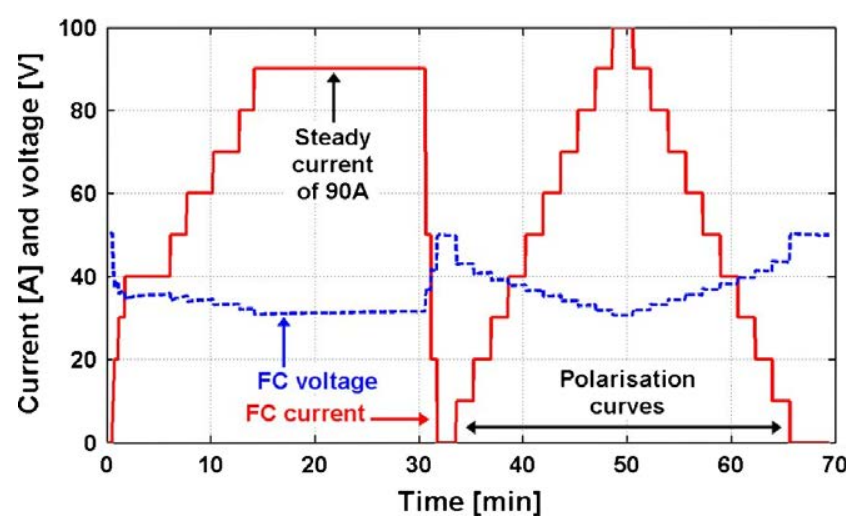

Fig. 3. Example of short reference test record: FC current and stack voltage response (ambient surrounding temperature close to $+15^{\circ} \mathrm{C}$ ).
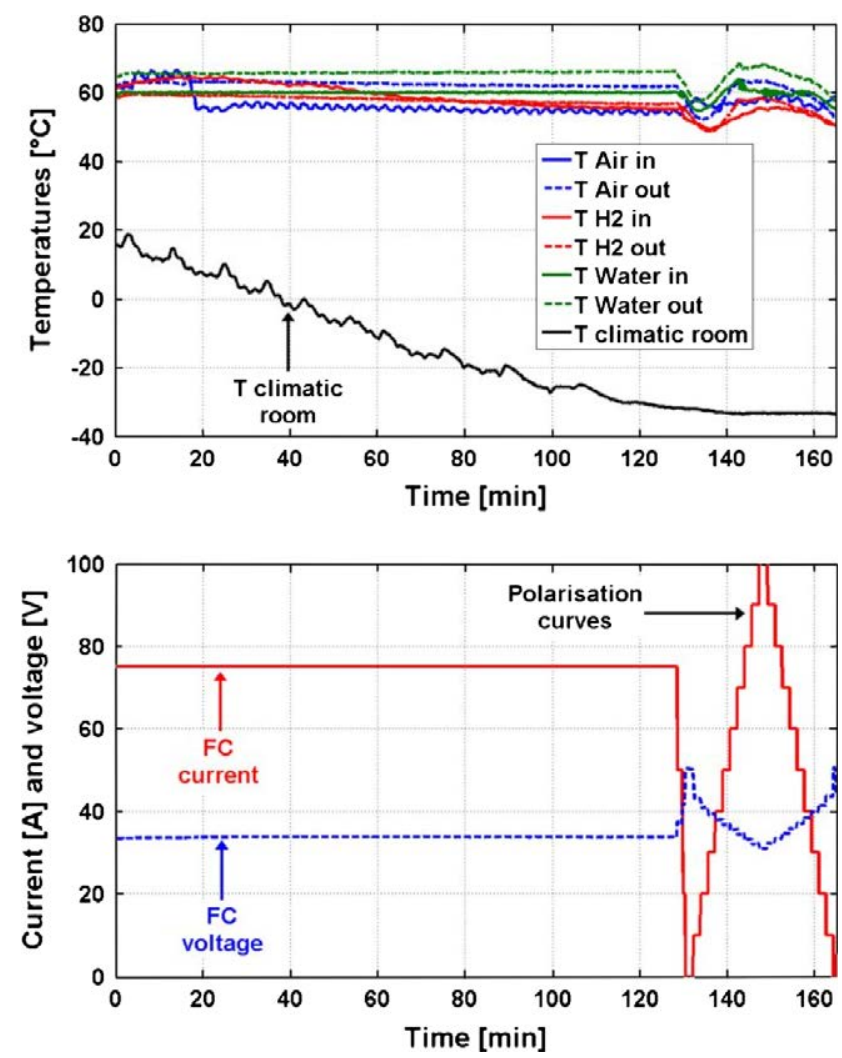

Fig. 4. Low temperature test performed with a load current of $75 \mathrm{~A}$ and a climatic room temperature reduced to $-34{ }^{\circ} \mathrm{C}$ about.

reached (linked with the technical capabilities of the climatic chamber), some caution is taken so that the stack power output is stabilised. After that, two consecutive polarisation curves are recorded, by increasing and decreasing the load.

With the test procedures so defined, the low temperature experiments could be performed for the load current values equal to $25 \mathrm{~A}, 50 \mathrm{~A}$ and $75 \mathrm{~A}$. The investigated FC had shown good quality performances during the four tests. As an example, some results obtained during the test conducted with a current of $75 \mathrm{~A}$ are shown in Fig. 4. During this experiment no external warm source was heating the stack but the inlet streams had the same temperature (or slightly higher) references than the stack $\left(+60\right.$ to $+65^{\circ} \mathrm{C}$ ). The electrical power obtained for $75 \mathrm{~A}$ was around $2530 \mathrm{~W}$ at the beginning of the test when the surrounding temperature was 
about $+15^{\circ} \mathrm{C}$. Then, the temperature reference in the climatic chamber was decreased progressively down to $-34^{\circ} \mathrm{C}$. For the lowest surrounding temperatures achieved, the thermal power delivered by the stack was sufficient to heat the fluid in the temperature circuit to the requested level of $60^{\circ} \mathrm{C}$. Nevertheless, it can be observed from Fig. 4 that it was quite difficult to maintain some gas temperatures of $65^{\circ} \mathrm{C}$ at the gas inlets of the $\mathrm{FC}$ stack ( $T$ Air and $T H 2$ ). For a temperature of $-34^{\circ} \mathrm{C}$ in the chamber, the hydrogen and air inlet stream temperatures were rather equal to $55-56{ }^{\circ} \mathrm{C}$. The FC power output was approximately constant, in the range $2528-2538 \mathrm{~W}$ during the $75 \mathrm{~A}$ steady-state phase. After this period, two polarisation curves were recorded. The surrounding temperature was still close to $-34^{\circ} \mathrm{C}$. For $100 \mathrm{~A}$, a maximal power of $3.1 \mathrm{~kW}$ was obtained from the stack. After the polarisation curve records, the test was finally stopped.

During the three low temperature experiments, the FC power levels reached for each one of the constant load currents (25 A, $50 \mathrm{~A}$ and $75 \mathrm{~A}$ ) have not varied dramatically during the decreases of the surround temperatures from $20^{\circ} \mathrm{C}$ down to $-34^{\circ} \mathrm{C}$. Nevertheless, during these tests and in comparison with the polarisation curve tests performed at ambient temperature $\left(+15^{\circ} \mathrm{C}\right)$, some slight decay of the electrical powers delivered by the stack was observed. For instance, for the maximal load of $100 \mathrm{~A}$, an electrical power of a few $10 \mathrm{~W}$ was lost. This slight drop down of the performances cannot be attributed to particular physical problems encountered within the FC stack. It should rather be related with the temperature constraints exerted on the complete test module placed in the chamber. The main problem highlighted by all the low temperature tests was in fact the following one. In the cold surround, for temperatures close to $-40{ }^{\circ} \mathrm{C}$, the thermal powers delivered by the heating gas lines placed upstream of the stack were not sufficient to keep some temperatures of +60 to $+65^{\circ} \mathrm{C}$ at the stream inlets. Obviously, this trouble occurred especially when the reactive gas flow values were low (e.g. for gas amounts related with a $25 \mathrm{~A}$ current). Some quite rapid decreases of the gas inlet temperatures (and stack temperature as well) can notably be observed in Fig. 4 when the lowest current values of the polarisation curve records are applied. In these phases, the gas flows could not carry so much heat from the humidifiers, which are located on the main part of the test bench, towards the gas inlets of the stack. And thus, some small local condensation/saturation phenomena could occur in the gas pipes. In fact, the problem was not so pregnant for the low temperature levels that could be reached in the tests achieved. But it can be guessed that if analogous climatic tests had to be performed at still lower temperature levels (possibly $-60^{\circ} \mathrm{C}$ ), the problem may have been emphasised. In such a case, in order to avoid any condensation in the gas pipes, the gas humidification would have to be probably reduced consequently. The amounts of deionised water to be injected into the humidification columns would have been decreased, which would certainly lead to the drying of the stack membrane and thus contribute to a larger decay of the FC delivered powers.

A comparison is made in Fig. 5 between different polarisation curve records (load current-stack voltage curves displayed using some 9th order polynomial fittings) performed on the one hand during the short reference test presented in Fig. 3 (i.e. in the reference conditions, at ambient surrounding temperature close to $+15^{\circ} \mathrm{C}$ ) and on the other hand during the low temperature test performed for a load current of $75 \mathrm{~A}$ (depicted in Fig. 4). The stack performance characteristics obtained in both cases are very close. A weak difference of performances (inferior to $1 \mathrm{~V}$ ) can possibly be detected between the polarisation curves recorded by increasing the load and with those measured by decreasing the current. The slight improvement of the stack voltage during the decreasing polarisation curves is likely to be explained by some better membrane hydration during the maximum to zero load current phases.

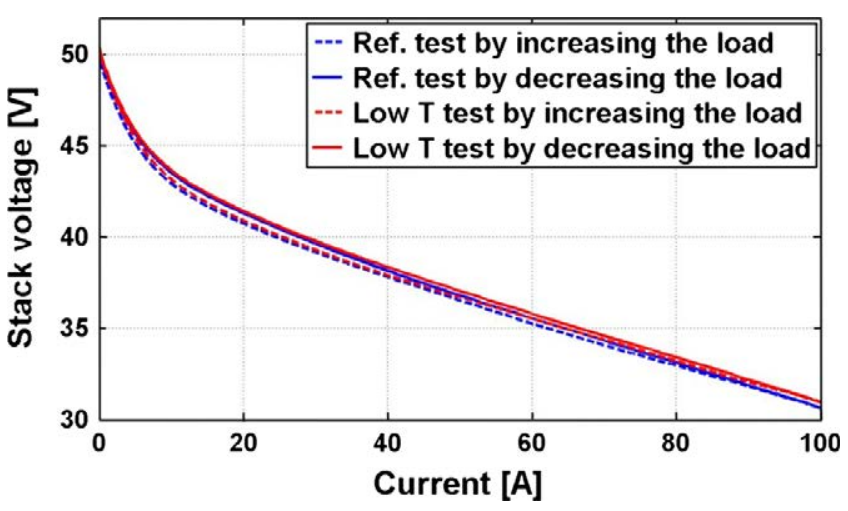

Fig. 5. Example of comparison between different polarisation curve records performed: during a short reference test (i.e. at ambient temperature of $+15^{\circ} \mathrm{C}$ ), during the low temperature test with a $75 \mathrm{~A}$ steady-state phase (in surround temperature close to $-34^{\circ} \mathrm{C}$ ).

The production of water through the chemical reaction is also greater for the higher current values and thus, when the current is decreased stepwise, the membranes have some higher hydration rates and thus better proton conductivities. This "hysteresis" occurrence is frequently observed by FC experimenters during polarisation curve records whatever the set of operation conditions [37].

Some statements can be made from the analysis of the different technical problems described above in the design of the future FC systems to be embedded on aircraft board. First, the peripheral system components of the system have to be properly selected according to the lowest surrounding temperature level. For low temperature tests, especially the heating gas lines placed upstream and downstream of the stack are matters of concern. In a more general way, the thermal packaging (component, gas pipe insulation and integration of elements into a housing) appears as being critical for the long-term running of the FC system at subzero temperatures and for the achievement of stable performances in these conditions. No freezing of water should occur in the stack itself, neither in the gas and fluid loops of the peripheral ancillaries. To reach this aim, a strong reliability of the ancillaries and overall FC system management (e.g. heating elements, pump of the temperature control circuit) is mandatory. In that way, the sensors and the electric/electronic components should also be protected against the presence of frost and water (due to possible encountered various condensation phases).

To conclude on these tests, we can point out that no particular degradation of the stack performances could be observed after the experiment completion.

\subsection{Ground survival temperature tests}

Different ground survival temperature tests were realised during the project. One of them has been conducted with a surrounding temperature ( $T$ climatic room) equal to $-20^{\circ} \mathrm{C}$. The course of this experiment and its results are described hereafter.

So, at the beginning of the test, a drying procedure was first applied in order to purge the liquid water possibly remaining inside the FC assembly and within the gas pipes as well (Fig. 6). The shut-down strategy of FC systems and the related drying procedures are identified to be some key-factors influencing the start of FC stacks under freeze conditions. In [20], it is found that a higher degree of dryness in the stack leads to a significant improvement in the freeze start performance because the water absorbing capacity of the FC membrane increases and thus also the time until its saturation. According to Schießwohl et al., if this saturation takes 

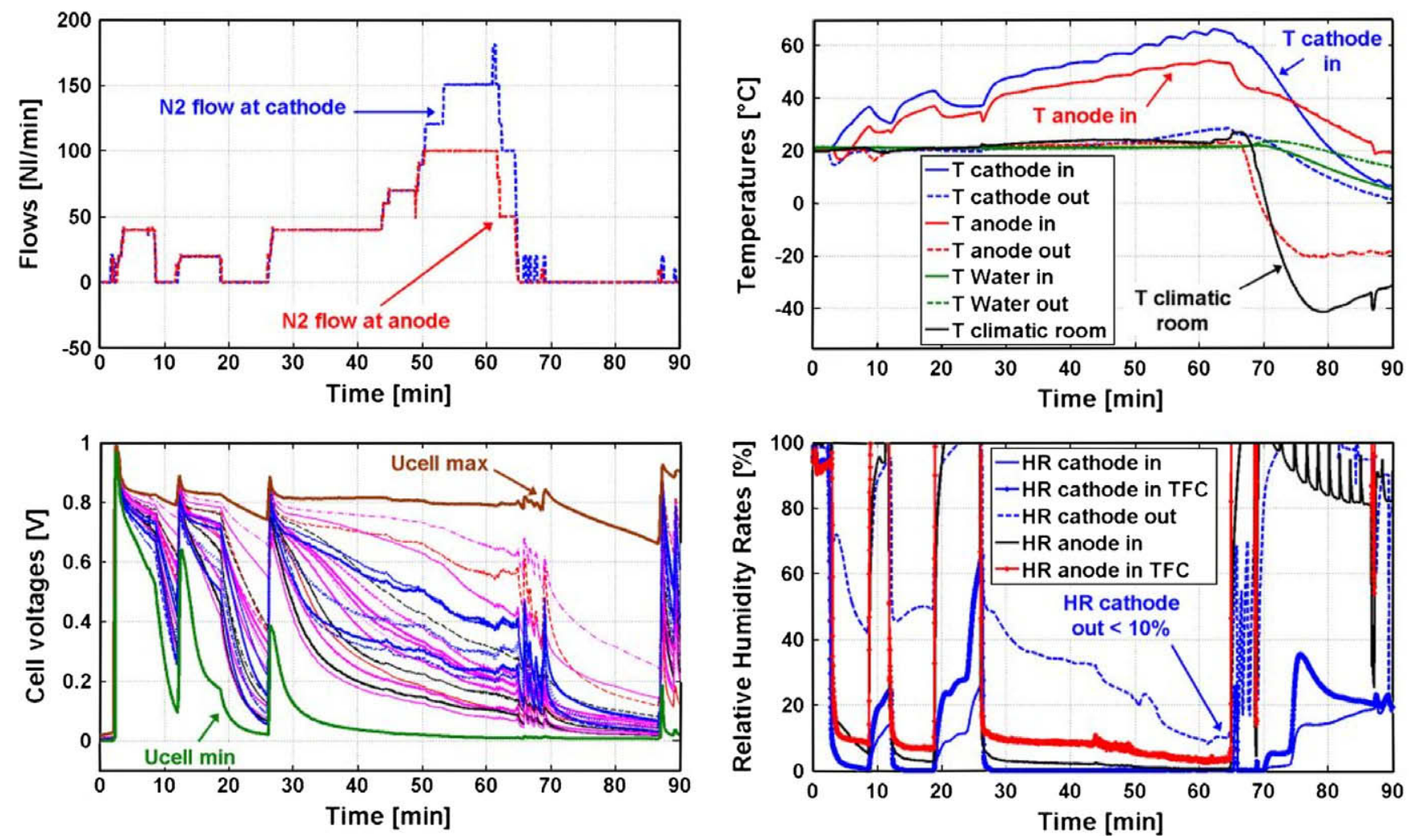

Fig. 6. Drying procedure applied before the ground survival test.

place after that the temperature of the MEA reaches $0{ }^{\circ} \mathrm{C}$, no significant ice-formation occurs. Cho et al. $[14,38]$ have found that FC freeze/thaw cycling between -10 and $80^{\circ} \mathrm{C}$ leads to cell performance degradation if water is not purged from the FC before freezing.

In the ground survival temperature test, the stack was purged using dry nitrogen, with some different gas flow values, up to $100 \mathrm{Nl} \mathrm{min}-1$ and $130 \mathrm{Nlmin} \mathrm{m}^{-1}$ at anode and cathode respectively, and with some fluid temperatures reaching about $+60^{\circ} \mathrm{C}$. During this period of about $1 \mathrm{~h}$, the stack temperature was close to $+20^{\circ} \mathrm{C}$. The gas flows were applied until the relative humidity sensor at cathode outlet (HR cathode out) could show a value inferior to $10 \%$. The value given by this humidity sensor has been chosen as reference because some higher amounts of water are generally present at the cathode side of PEMFC stacks. The nitrogen flows applied to inert the FC led to more or less pronounced dropdowns of the various cell voltages. Then, the temperature reference inside the climatic chamber was decreased to $-20^{\circ} \mathrm{C}$ with the test bench switched off (FC and all bench parts inactive). This temperature was hold for approximately $3 \mathrm{~h}$ with the aim to simulate an aircraft cold soak. Note that to satisfy future aircraft requirements and to avoid any additional storage of gas, nitrogen should probably be replaced by air and hydrogen to purge the FC assembly.

Thereafter, the stack was heated up to $+15^{\circ} \mathrm{C}$ by the means of the temperature control loop, and in particular using the available electrical heater. During that time, no electrical power output was delivered from the stack. After that the temperature control loop reached the specified temperature (in Fig. $7, T$ Water in $=+15^{\circ} \mathrm{C}$ ), the gas supply was started. The gases (nitrogen) were heated upstream of the stack by the heating pipes until $+15^{\circ} \mathrm{C}$. A slight increase of the stack Open Current Voltage (OCV) could be observed when the nitrogen streams were applied (from $t=58 \mathrm{~min}$ ). This phenomenon is likely to be basically explained as follows. In the FC idle mode, some traces of reactive gases (i.e. hydrogen and oxygen of the air) were remaining in the GDLs and inside the electrodes. The nitrogen flows have "pushed" theses (minor) quantities of reactive gases towards the reaction interfaces, which led to higher oxygen and hydrogen partial pressures at these interfaces, and thus to higher cell voltages. Besides, it can also be observed from Fig. 7 that the elevation of the temperatures at the FC inlets and outlets, and inside the stack, led evidently to lower relative humidity rates. Before starting to load the FC, it was checked that the stack had no problem by conducting a leak test. This kind of test, sometimes called pressure test, is designed to identify any defective stack components such as broken, cracked MEAs or defective sealing, and stack assembly errors like displaced gaskets. To reach this aim, the cathode compartment was first pressurised with nitrogen at about 200 mbar rel. while the anode compartment was sealed at ambient pressure. Then, the pressures in both compartments were monitored as a function of time. No singular evolution of the pressure levels related with any leakage between anode and cathode or with the external surround was detected. Some additional explanations and details about the procedures related with leak tests can be found in $[35,36]$ for instance.

Here, it is important to note that the heating of the temperature circuit, from about $-13^{\circ} \mathrm{C}$ to $+15^{\circ} \mathrm{C}$, took about $1 \mathrm{~h}$. As for the complete test phase depicted by Fig. 7, its duration was close to $100 \mathrm{~min}$.

Once the leak test was completed, the stack was fed with air and hydrogen (Fig. 8). After reaching a gas temperature at stack outlet above $+5{ }^{\circ} \mathrm{C}$, the humidification of the reactive gases was started. When a voltage of $900 \mathrm{mV} /$ cell was obtained, the stack current was increased quite slowly and with cautious. The stack and gas inlet temperatures increased further and the temperature of the external heating source was set to $+60^{\circ} \mathrm{C}$. During the heating-up of the stack, the load current was gradually increased to $100 \mathrm{~A}$ with the surrounding temperature ( $T$ climatic room) still 

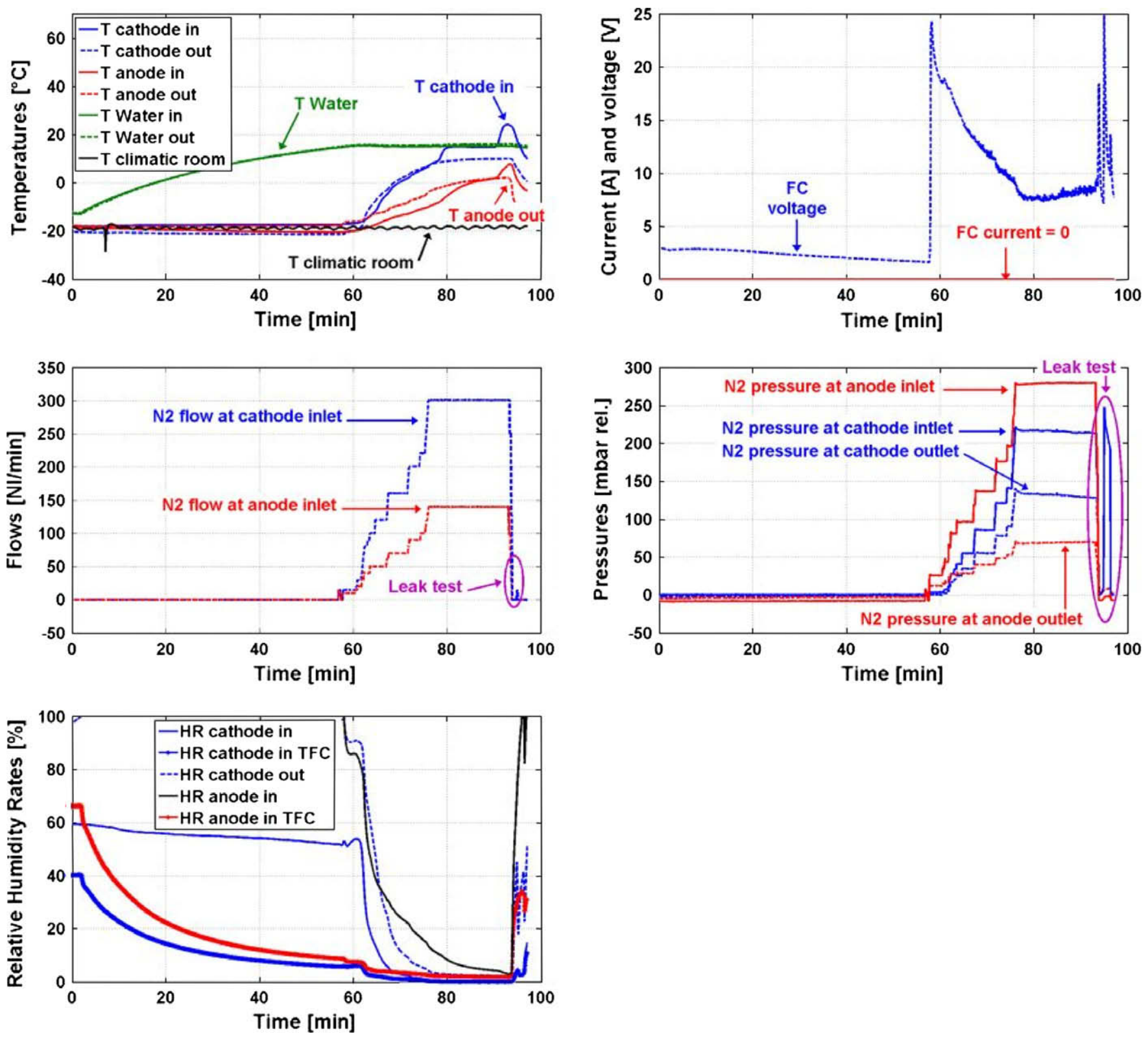

Fig. 7. Stack heating using an external warm source and leak test.

set to $-20^{\circ} \mathrm{C}$. Then, the stack could provide usual performances. An electrical power slightly higher than $3 \mathrm{~kW}$ was finally delivered for the load current value of $100 \mathrm{~A}$ and for a stack temperature around $+60{ }^{\circ} \mathrm{C}$. Such a power level was already reached during the short reference test (see Section 3.1).

Again, this climatic experiment has shown the importance of the system facet in the achievement of fine FC performances. The key-role of the peripheral devices placed around the stack has been highlighted by the test while the need of thorough ancillary design and control has been emphasised. If a ground survival procedure has to be applied in future aircrafts equipped with embedded FC generators, some short FC start-up will probably be expected by the end-users. To enable such an efficient warm-up, especially the heater of the FC temperature control loop will have to be sized and managed properly to offer some sufficient capability in term of power delivery. The drawback of the active method used in this test to heat the stack is obviously the energy consumption of the heater and the resulting need of additional energy storage devices like buffer batteries. Not only the heating source has to be well designed, the architecture of the temperature control circuit is also of importance. One can also believe that the heating loop of this circuit can be optimised by minimising the volume of the fluid to be heated in order to accelerate the start-up. In [20], two temperature control circuits ("Mini-Loop" and "Maxi-Loop") are implemented in the depicted FC system. A small "Mini-Loop" consists only of the stack, the cooling pump and the heating system. This loop is specifically used for freeze start experiments. The content of the cooling fluid is reduced and the thermal mass of the whole loop including the components is reduced to one third of the "MaxiLoop" thermal mass.

Even though it can be stated that no particular problem occurred with the stack during the ground survival temperature test, the point at issue remains probably the stack lifetime and reliability in these test conditions, that is to say if similar tests have to be repeated a significant number of times; i.e. over freeze-thaw cycles. As already suggested in the introduction, the most significant 

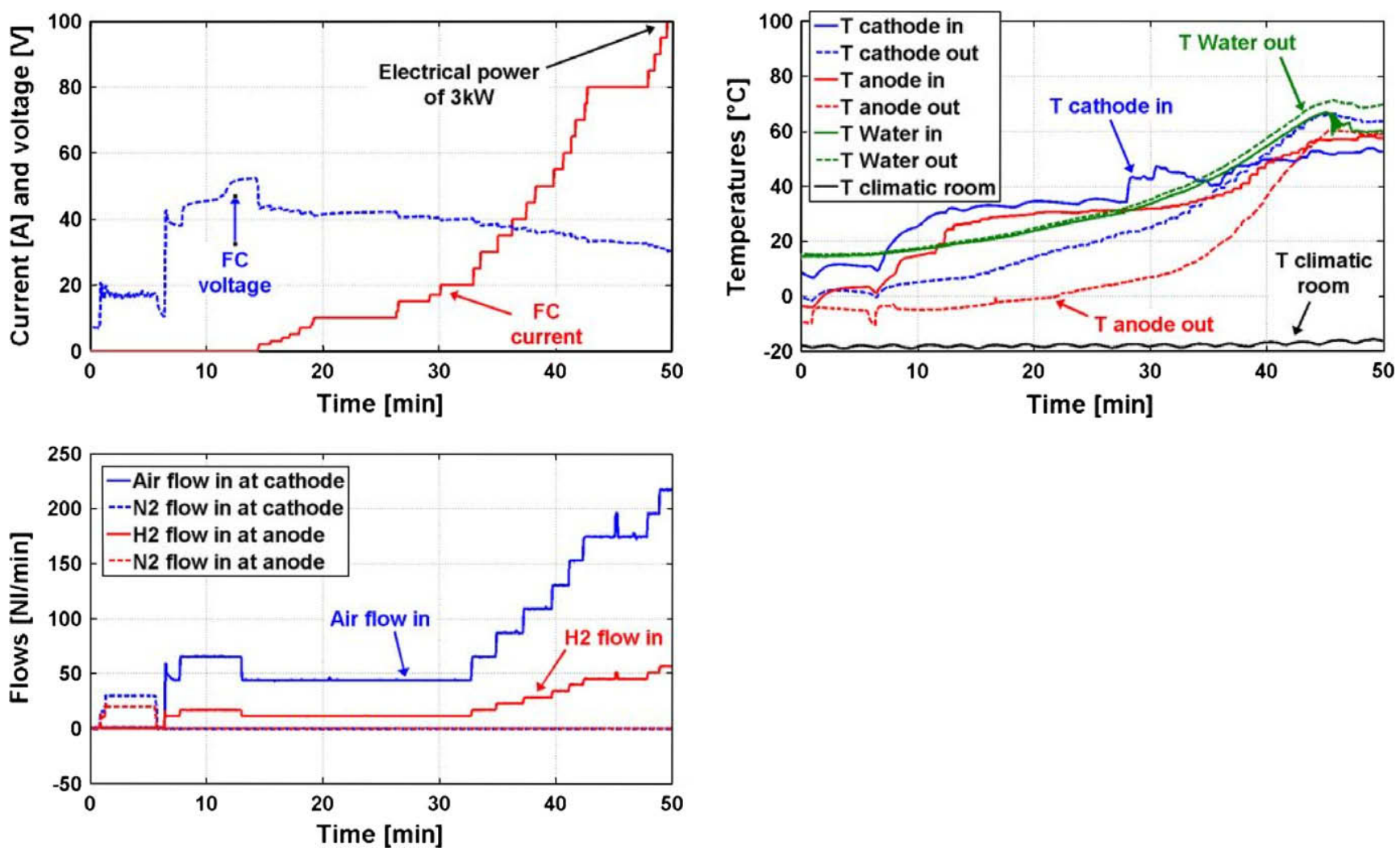

Fig. 8. Gradual increase of the load from 0 A to 100 A. Start of the load at FC temperature of $+15^{\circ} \mathrm{C}$. Environment temperature close to $-20{ }^{\circ} \mathrm{C}$.

problem encountered in such a climatic experiment might be related with the formation and presence of frozen water inside the FC assembly. Indeed, the ice may damage the MEAs causing some cracks in the membranes [12] or possibly some catalyst layer delamination [9]. The physical degradation of different MEAs undergoing 30 freeze/thaw cycles between -40 and $70^{\circ} \mathrm{C}$ have been investigated by Kim et al. [39,40]. The delamination of the catalytic layer, especially in the areas of the gas channels, could be shown by Scanning Electron Microscopy (SEM) images. It is obvious that lowering the water content within the MEAs can be an effective method to prevent the stack from such degradation factors. Nevertheless, the behaviour of the current MEAs during the successive phases of drying and hydration needs to be better evaluated in term of durability. Indeed, it is believed that the mechanical stress induced by the multiple swelling of the membranes can also lead to the formation of cracks and pinholes. In this context, the accurate evaluation of the possible methodologies used for the shut-down of the FC generators is certainly an important task for the future. To avoid some degradation caused by the cold start-up, several stack drying strategies could be selected and the effect of the purge methods could be better evaluated. To reach this aim, more fundamental research works would be needed. The aim would be to investigate the impacts of various parameters linked with the purging methods. For example, the stack drying can be applied when the stack is at elevated temperatures, and it can be more efficient in these conditions. The purge duration can be another decisive operating parameter controlling the cold-operation or the cold-start performance. Some other factors (gas inlet temperatures, gas flow values) are also concerned. The underlying problem is probably related to the selection of appropriate criteria to know the amount of water or moist in the stack. The measurement of the gas relative humidity rates (and/ or the computing of gas dew point temperatures) can be used to reach this aim but the sensors currently used on the test bench are expensive and they might be not so adapted for the development of price-competitive embedded FC systems. A measurement of the stack impedance, performed on-line at high load current frequency (in the range $1-10 \mathrm{kHz}$ ), would probably be more convenient to estimate the amounts of water inside the polymer membranes [41]. In their experimental work, Ge and Wang [42] studied the complete start-up process including gas purge, cooldown, start-up from subfreezing temperatures and warm-up. They measured the FC impedance at $1 \mathrm{kHz}$ and found out optimal purge duration. A cell high frequency resistance relaxation due to water redistribution in the MEA after the purge was noticed. In further experimental studies, such impedance measurements could also be associated to the use of the experimental design methodology $[21,22,43]$, first to estimate the impacts of the various physical factors related with the adopted purging methods and then to prepare some optimised drying scenarios. Such a methodological approach would be surely suitable to better evaluate the roles of the drying/ hydration sequences over the stack lifetime.

Some attempts to perform other ground survival temperature tests at lower temperature levels in the climatic chamber (between $-37^{\circ} \mathrm{C}$ and $-20^{\circ} \mathrm{C}$ ) were also done. Some drying procedures as described above were first applied and the temperature references of the climatic room were set to the selected investigated levels. Unfortunately, after several hours in the cold surround, the temperature control circuit, or at less some parts of this circuit, were found as frozen, or the cooling medium had a too low viscosity value. The rotation of the pump was still possible but no acceptable cooling flow value could be obtained during these experiments, even if the adopted glycol-based cooling fluid was normally able to operate at temperatures up to $-36^{\circ} \mathrm{C}$. It can be remarked that the deactivation of the cooling pump in the start phase can possibly be included in some freeze start-up strategies with the aim to 
improve FC start times, as stated in [20]. However, it is not clear yet how such a cooling fluid management can influence the stack degradation due to inhomogeneous temperature profiles in the FC assembly.

A test was performed with a new temperature reference specified to the climate chamber equal to $-22{ }^{\circ} \mathrm{C}$. Then, the objective was to obtain a higher temperature at stack inlet using the heater of the temperature loop (active heating method). This operation was here rather difficult since the temperature increase of the fluid could only be observed in the vicinity of the heater. The cooling medium was almost blocked. As a consequence, a new control strategy of the heater had to be developed. The limitation of the heating power during this particular phase of the start-up has been implemented to avoid too high temperature levels in close proximity to the heater. The temperature reference of the climatic room was set to $-18^{\circ} \mathrm{C}$. Some flushes of the FC temperature circuit were also required to evacuate some air bubbles detected in the pump. The temperature at stack inlet could finally be increased to temperatures ranging from $+15{ }^{\circ} \mathrm{C}$ to $+20^{\circ} \mathrm{C}$. A leak test was performed with nitrogen. The cathode compartment was pressurised at 300 mbar rel., the anode was sealed at ambient pressure and no leakage was observed in the stack. The same operation was done by pressurising the anode too. No problem induced by the frozen or blocked control circuit could be observed after the various trials of ground survival temperature tests. Since no leakage was detected in the stack, the start-up procedure of the FC was started. The surrounding temperature was still equal to $-18^{\circ} \mathrm{C}$. A temperature reference of $+60^{\circ} \mathrm{C}$ was set for the FC. Some humidified reactive gas flows were applied. Then, the load current was increased until $80 \mathrm{~A}$. The FC could demonstrate some usual behaviours and performances during the experiment but the load current had to be stopped prematurely because again, some air bubbles were present in the stack cooling loop. However, a maximal electrical power of $2610 \mathrm{~W}$ could be reached. Finally, the equipment (the stack, the test bench as well as the climatic room) was switched off.

These additional tests have revealed some technological malfunctions of the temperature control circuit. When a surround temperature value below $-20^{\circ} \mathrm{C}$ was applied during several hours (corresponding to one night approximately), the adopted heattransfer medium became too viscous and the flow in the circuit could not be obtained with the pump used for the test. The properties of the cooling fluid, and in particular the viscosity value at low temperatures, should be better investigated in further experiments. The test of the cooling pump capability as well as the improvement of the heater control/management, during start-up phases at temperatures lower than $-20^{\circ} \mathrm{C}$, are some other important issues. Moreover, the large variations of the temperature inside the heat-transfer loop might lead to the formation of air bubbles. This technical problem has to be solved as well.

\subsection{Operating low temperature tests}

Some test results about an operating low temperature experiment performed with a surround temperature of $-9{ }^{\circ} \mathrm{C}$ are described and analysed in this subsection.

First, a purging process was realised by applying some reactive gas flow values of $100 \mathrm{Nl} \mathrm{min}^{-1}$ or even higher (up to

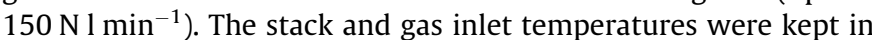
the range $+25^{\circ} \mathrm{C}$ to $+15^{\circ} \mathrm{C}$. Then, a temperature reference of $-9{ }^{\circ} \mathrm{C}$ was set for the climatic room and during the same time interval, the gas inlets were heated with the aim to accelerate the drying of the stack. The environment temperature was fixed at $-9{ }^{\circ} \mathrm{C}$ during about $3 \mathrm{~h}$. After this period, the temperature in the temperature control circuit of the FC was found as reasonably uniform: some values of $-9{ }^{\circ} \mathrm{C}$ and $-6{ }^{\circ} \mathrm{C}$ were measured at stack inlet and outlet. Then, some reactive gas flows were set $\left(14 \mathrm{~N} 1 \mathrm{~min}^{-1}\right.$ and $55 \mathrm{~N} 1 \mathrm{~min}^{-1}$ for the air and for the fuel respectively) and the FC was started-up by increasing the load current from $0 \mathrm{~A}$ to 25 A quite carefully and slowly, in a time period of $15 \mathrm{~min}$ (Fig. 9). On the contrary to the series of ground survival tests, the heater of the temperature control circuit was off during the whole experiment. So, in this case, the FC heating could be considered as passive since the stack warming was ensured by the thermal losses of the stack itself. The heat transferred by the reactant gases to the stack can also be considered in the warming process of the FC assembly. However, taking into account the large thermal capacity of the set composed of the stack with its temperature circuit, the energy brought by the streams has probably a limited impact on the global FC heating. In any case, the cold start was successful. A stable electrical power of about $980-990 \mathrm{~W}$ could finally be reached after 40 min of constant operation at 25 A (Fig. 9). The dispersion of the cell voltage values was found as usual. The maximal cell voltage was around $780 \mathrm{mV}$ and the minimal cell voltage was close to $740 \mathrm{mV}$. Such low cell voltage variability can be considered as a proof of good FC state-of-health.

After the cold start-up phase at $-9{ }^{\circ} \mathrm{C}$ (increase of the load current to $25 \mathrm{~A}$ and steady-state operation), a short reference test was performed. Again, the stack could demonstrate usual performances. An electrical power around $2825 \mathrm{~W}$ was delivered during the steady-state operation at $90 \mathrm{~A}$ and then, a maximal electrical power of $3050 \mathrm{~W}$ was reached at $100 \mathrm{~A}$ during the polarisation curve measurements. During this test, some slight problems were encountered again with the insufficient insulation and inadequate heating of the reactive gas pipes upstream of the stack. In the cold surround, it was still difficult to maintain some gas temperatures higher than $+60^{\circ} \mathrm{C}$ at stack inlets, in particular at the anode side and for the low gas flow values.

Another operating low temperature test was performed with a surround temperature of $-18^{\circ} \mathrm{C}$. Compared to the test described previously, the experiment course occurred in a similar way. Note that the stack was first heated through the reactive gases coming from the main part of the test bench. Thus, the increase of the load current was done from a stack temperature close to $-9{ }^{\circ} \mathrm{C}$. The start-up of the FC was first considered as successful since a power of $1500 \mathrm{~W}$ was reached at $40 \mathrm{~A}$. But then, some failures occurred on several cells and some anode-cathode leakages were detected. Some membrane perforations can be assumed. The problem may be attributed to the formation of ice inside the stack, either due to insufficient water draining out of the FC during the previous drying procedure or caused by too high amounts of water produced by the reaction at subzero temperatures. The historical related with the numerous sorts of FC operation conditions encountered prior to the test in question should also be considered to explain the failure. Some diagnosis procedures, similar to those described in [25], were applied in order to detect the few failed cells. These cells were removed and replaced by IRD [30]. Then the stack could be operated again.

The operating low temperature tests proved to be quite complex to perform, and the related test conditions were found as sever from the stack integrity point of view. After these experiments, it is patent that some particular problems have to be investigated more deeply in the future to ensure higher reliability and durability of FC stacks facing subzero temperatures. For instance, the effect of the initial current density on the cold start-up (using a step of load current or a ramp with given durations) has to be taken into account. Kagami et al. [26] discussed experimental and simulation results of a single PEMFC. They studied the influence of temperature and current density under isothermal conditions. They observed that cell performance decreased quickly at lower cell temperature and higher current densities. The role of the heat brought to the stack through the gas feeding should also be considered. The work of Yan et al. can be mentioned [9]. Freeze start 

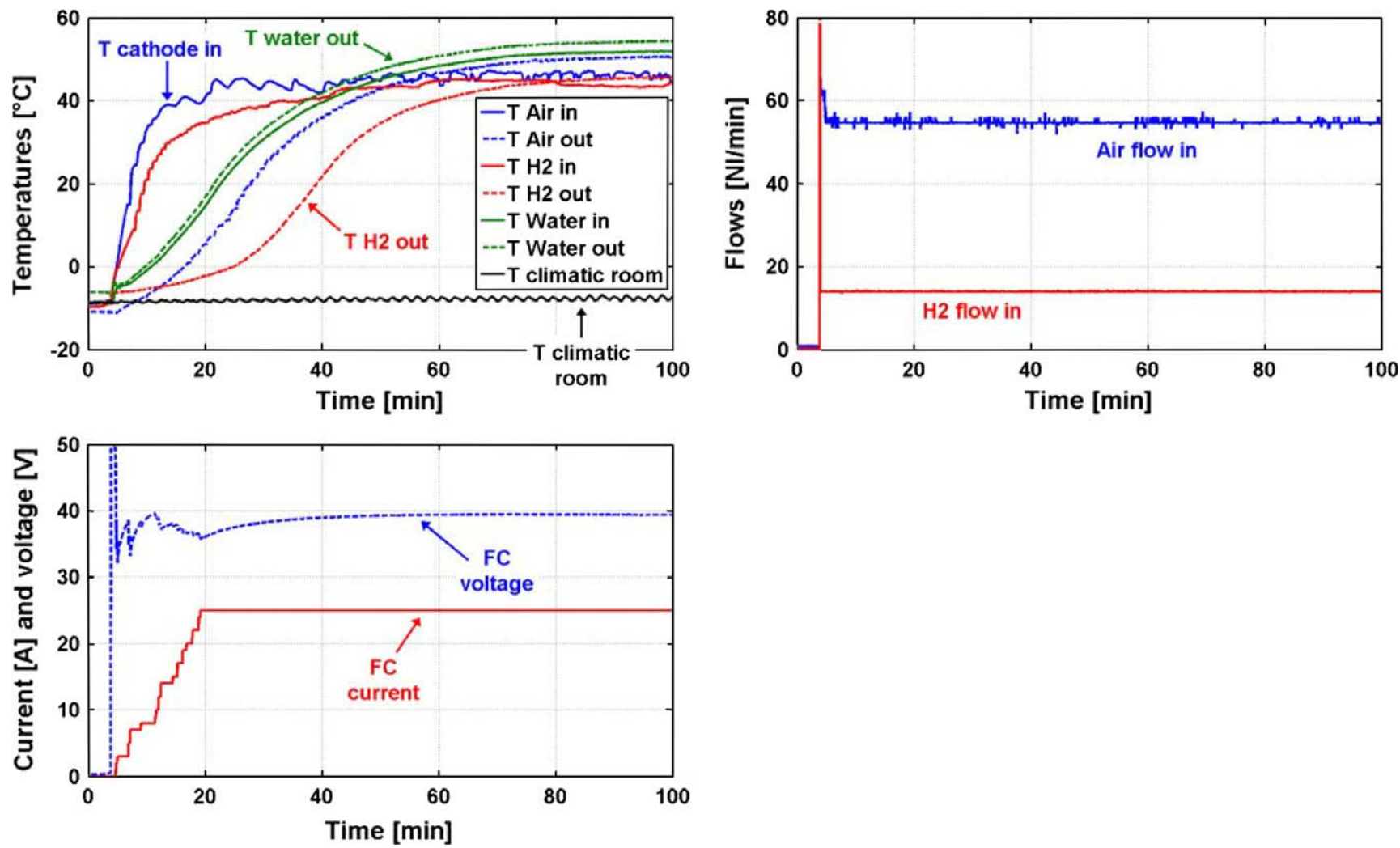

Fig. 9. Operating low temperature test with a temperature reference for the climatic room equal to $-9{ }^{\circ} \mathrm{C}$.

experiments have been carried out under different conditions with a temperature variation from -5 to $-15^{\circ} \mathrm{C}$. A successful start occurred at $-5^{\circ} \mathrm{C}$ when the cell was insulated and pre-purged. At $-10^{\circ} \mathrm{C}$, the air stoichiometry and temperature were increased. Oszcipok et al. [21-23] found out that dry membranes and high air flow rates have a positive impact on the cold start.

Some experiments should also be planed to find out how the material and the design of the bipolar plates (graphite/composite or stainless steel) can affect the decay of the output power during cold start-up or low temperature operations. The tests should also include some investigations about the role of the MEA properties, the membrane thickness and therefore be related with the studies of researchers working more precisely on the material aspects of FC operated in low temperature environments. For example, the results of the work done by Kim et al. $[39,40]$ can be considered: they found that thinner membranes lead to less degradation due to ice formation.

The FC could be started-up but the phase duration of the rehumidification process might be not long enough.

- "Too long" drying of the membranes with nitrogen can damage them (depending on the gas flow and stack temperatures). "Too short" drying of the membranes could not be sufficient to avoid the presence of water remaining inside the stack.

- To start-up the FC, the load current was increased. Obviously, this produces some water inside the stack.

- It is difficult to find the right moment for the start-up of the humidification. Normally, that shall not be done as long as the stack temperature is not higher than $0^{\circ} \mathrm{C}$. During the phase where the stack temperature increases from a negative value to $0{ }^{\circ} \mathrm{C}$, the gas flows are dry, which represents also very difficult conditions for the stack. The duration of the phase where the stack temperature increases from a negative value to $0{ }^{\circ} \mathrm{C}$ depends on the level of the low start-up temperature.

\section{Conclusion}

The cold-operation and start-up abilities of a PEMFC stack were investigated experimentally by performing a variety of climatic tests. The different temperature constraints exerted on the stack the various FC system operating strategies were defined according to airplane applications and requirements.

In one test, the FC was started in conventional environment conditions and operated while the surround temperature was decreased gradually down to $-34^{\circ} \mathrm{C}$. The stack behaviour and its performances in the experiment were found as usual. The amount of heat generated by the stack itself and mainly dissipated within the temperature control circuit was enough to keep the water inside the FC assembly away from freezing. Though, some minor problems at the system level were observed during the test. Slight nonadapted thermal conditioning of the gas flowing in the pipes placed upstream and downstream of the stack was detected. The test has also suggested that a strengthen reliability of the FC system peripherals must be ensured to avoid any test bench and/or FC shut-down. This is actually one essential condition to preserve the stack from any bad and unsafe subzero experience [44].

The start of the FC placed in idle mode in low temperature environments was also of concern in other tests. So, two strategies of FC start-up were considered.

The active-assisted cold start-up of the FC, through the external warming by the FC temperature control loop, was first studied. No major trouble occurred during the tests. Nevertheless, they have laid stress on different technological issues, as the importance of the system thermal packaging and the interest of having a temperature control loop reduced in size to enable quicker start-ups. In this part, some drying procedures of the FC assembly had also to be defined and applied. They were found as effective to purge the stack from any residual water droplets. Anyway, some stack impedance measurements allowing some better and probably 
cheaper determination of the FC membrane hydration state should be used in further works and applications. Another essential and more fundamental question concerns the impact of the successive drying/humidifying phases on the FC reliability and durability.

The problematic of the FC self start-up (passive start-up made without external heating) was also approached. An example of successful self start-up has been presented. The interest of the procedure lies in the possible limited energy consumption of the peripheral system components, leading to a better respect of the overall FC system efficiency. Some technical hitches were also encountered with the FC temperature control circuit during startup trials conducted at surround temperatures lower than $-20^{\circ} \mathrm{C}$. The underlying troubles on the circuit came on the one hand from a not totally adequate cooling fluid (too viscous medium), and on the other hand from large temperature gradients observed in quite restricted periods. The problems identified could not be completely solved. However, some specific procedures were implemented in the software dedicated to the test bench control in order to avoid any troublesome drift of important physical parameters (e.g. excessive temperatures on the temperature control loop, especially in the vicinity of the heater).

The complete series of climatic tests has shown that the issues of the FC system survivability and start-up in subzero temperature environments are of paramount importance for the development of the next aircraft applications.

\section{Acknowledgments}

This work was done in the framework of the CELINA project. The EU is gratefully acknowledged for its financial support.

\section{References}

[1] Pohl HW, Malychev VV. Hydrogen in future civil aviation. Int J Hydrogen Energy 1997;22(10-11):1061-9.

[2] Dollmayer J, Bundschuh N, Carl UB. Fuel mass penalty due to generators and fuel cells as energy source of the all-electric aircraft. Aerosp Sci Techno 2006;10(8):686-94.

[3] Document RTCA/DO-160E (Radio Technical Commission for Aeronautics Document), Environmental Conditions and Test Procedures for Airborne Equipment. International standard for environmental testing of commercial avionics. RTCA, Inc.; December 9, 2004.

[4] Corbo P, Migliardini F, Veneri O. Experimental analysis of a $20 \mathrm{kWe}$ PEM fuel cell system in dynamic conditions representative of automotive applications. Energy Convers Manage 2008;49(10):2688-97.

[5] Choi KS, Kim HM, Yoon HC, Forrest ME, Erickson PA. Effects of ambient temperature and relative humidity on the performance of Nexa fuel cell. Energy Convers Manage 2008;49(12):3505-11.

[6] Lee C, Mérida W. Gas diffusion layer durability under steady-state and freezing conditions. J Power Sources 2007;164(1):141-53.

[7] Tajiri K, Tabuchi Y, Kagami F, Takahashi S, Yoshizawa K, Chao-Yang Wang. Effects of operating and design parameters on PEFC cold start. J Power Sources 2007;165(1):279-86.

[8] Ahluwalia RK, Wang X. Rapid self-start of polymer electrolyte fuel cell stacks from subfreezing temperatures. J Power Sources 2006;162(1):502-12.

[9] Yan Q, Toghiani H, Lee YW, Liang K, Causey H. Effect of sub-freezing temperatures on a PEM fuel cell performance, startup and fuel cell components. J Power Sources 2006;160(2):1242-50.

[10] Hou J, Yu H, Zhang S, Sun S, Wang H, Yi B, et al. Analysis of PEMFC freeze degradation at $-20^{\circ} \mathrm{C}$ after gas purging. J Power Sources 2006;162(1):513-20.

[11] Yun Wang. Analysis of the key parameters in the cold start of polymer electrolyte fuel cells. J Electrochem Soc 2007; 154:B1041.

[12] Guo Q, Qi Z. Effect of freeze-thaw cycles on the properties and performance of membrane-electrode assemblies. J Power Sources 2006;160(2):1269-74.

[13] Mac Donald RC, Mittelsteadt CK, Thompson EL. Effects of deep temperature cycling on Nafion 112 membranes and membrane electrode assemblies. Fuel Cells 2004;4(3):208-13.
[14] Cho EA, Ko JJ, Ha HY, Hong SA, Lee KY, Lim TW, et al. Characteristics of the PEMFC repetitively brought to temperatures below $0{ }^{\circ} \mathrm{C}$. J Electrochem Soc 2003;150(12):A1667-70.

[15] Ishikawa Y, Morita T, Nakata K, Yoshida K, Shiozawa M. Behavior of water below the freezing point in PEFCs. J Power Sources 2007;163(2):708-12.

[16] Shanhai Ge, Chao-Yang Wang. Cyclic voltammetry study of ice formation in the PEFC catalyst layer during cold start. J Electrochem Soc 2007;154:B1399.

[17] Hou J, Yi B, Yu H, Hao L, Song W, Fu Y, et al. Investigation of resided water effects on PEM fuel cell after cold start. Int J Hydrogen Energy 2007;32(17):4503-9.

[18] Wang H, Hou J, Yu H, Sun S. Effects of reverse voltage and subzero startup on the membrane electrode assembly of a PEMFC. J Power Sources 2007;165(1): 287-92.

[19] Oszcipok M, Zedda M, Hesselmann J, Huppmann M, Wodrich M, Junghardt M, et al. Portable proton exchange membrane fuel-cell systems for outdoor applications. J Power Sources 2006;157(2):666-73.

[20] Schießwohl E, Von Unwerth T, Seyfried F, Brüggemann D. Experimental investigation of parameters influencing the freeze start ability of a fuel cell system. J Power Sources 2009;193(1):107-15.

[21] Oszcipok M, Riemann D, Kronenwett U, Kreideweis M, Zedda M. Statistic analysis of operational influences on the cold start behaviour of PEM fuel cells. J Power Sources 2005;145(2):407-15.

[22] Oszcipok M, Zedda M, Riemann D, Geckeler D. Low temperature operation and influence parameters on the cold start ability of portable PEMFCs. J Power Sources 2006;154(2):404-11.

[23] Oszcipok M, Hakenjos A, Riemann D, Hebling C. Start up and freezing processes in PEM fuel cells. Fuel Cells 2007;7:135-41.

[24] Datta BK, Velayutham G, Prasad Goud A. Fuel cell power source for a cold region. J Power Sources 2002;106(1-2):370-6.

[25] Tajiri K, Tabuchi Y, Kagami F, Takahashi S, Yoshizawa K, Wang CY. Effects of operating and design parameters on PEFC cold start. J Power Sources 2007;165(1):279-86

[26] Kagami F, Ogawa T, Hishinuma Y, Chikahisa T. Therm Sci Eng 2002;10(3): 25-33.

[27] Pinton E, Fourneron Y, Rosini S, Antoni L. Experimental and theoretical investigations on a proton exchange membrane fuel cell starting up at subzero temperatures. J Power Sources 2009;186(1):80-8.

[28] Summary of the CELINA project on the Web site of the European Commission; 2008. <http://ec.europa.eu/research/transport/projects/article_3684_en.html>.

[29] Aircraft fuel cell team targets certification. Fuel Cells Bull 2006;(9):2.

[30] Web site of IRD Fuel Cell Technology; 2009. <http://www.ird.dk>.

[31] Candusso D, Harel F, De Bernardinis A, François X, Péra MC, Hissel D, et al. Characterisation and modelling of a $5 \mathrm{~kW}$ PEMFC for transportation applications. Int J Hydrogen Energy 2006;31(8):1019-30.

[32] Antoine C. Vapour pressures: new relation between pressures and temperatures. CR Hebd Seances Acad Sci 1888;107:681-4. 778-780, 836-837.

[33] Web site of National Instruments; 2009. <http://www.ni.com>.

[34] MATLAB ${ }^{\mathrm{TM}}$ Software. The MathWorks, Inc.; 2009. <http://www. mathworks.com>.

[35] Tian G, Wasterlain S, Endichi I, Candusso D, Harel F, François X, et al. Diagnosis methods dedicated to the localisation of failed cells within PEMFC stacks. J Power Sources 2008;182(2):449-61.

[36] Tian G, Wasterlain S, Candusso D, Harel F, Hissel D, François X. Identification of failed cells inside PEMFC stacks in two cases: anode/cathode crossover and anode/cooling compartment leak. Int J Hydrogen Energy, in press.

[37] Santarelli MG, Torchio MF. Experimental analysis of the effects of the operating variables on the performance of a single PEMFC. Energy Convers Manage 2007;48(1):40-51.

[38] Cho EA, Ko JJ, Ha HY, Hong SA, Lee KY, Lim TW, et al. Effects of water removal on the performance degradation of PEMFCs repetitively brought to $<0{ }^{\circ} \mathrm{C}$. J Electrochem Soc 2004;151(5):A661-5.

[39] Kim S, Mench MM. Physical degradation of membrane electrode assemblies undergoing freeze/thaw cycling: micro-structure effects. J Power Sources 2007;174(1):206-20.

[40] Kim S, Ahn BK, Mench MM. Physical degradation of membrane electrode assemblies undergoing freeze/thaw cycling: diffusion media effects. J Power Sources 2008;179(1):140-6.

[41] Bégot S, Harel F, Kauffmann JM. Design and validation of a $2 \mathrm{~kW}$-fuel cell test bench for subfreezing studies. Fuel Cells 2008;8(1):23-32.

[42] Ge S, Wang CY. Characteristics of subzero startup and water/ice formation on the catalyst layer in a polymer electrolyte fuel cell. Electrochim Acta 2007;52(14):4825-35.

[43] Wahdame B, Candusso D, Francois X, Harel F, De Bernardinis A, Kauffmann JM, et al. Study of a $5 \mathrm{~kW}$ PEMFC Using experimental design and statistical analysis techniques. Fuel Cells 2007;7(1):47-62.

[44] Bégot S, Harel F, Kauffmann JM. Experimental studies on the influence of operational parameters on the cold start of a $2 \mathrm{~kW}$ fuel cell. Fuel Cells 2008;8(2):138-50. 